\title{
北大别罗田榴辉岩的同位素年代学和岩石成因及其 在折返过程中的元素和同位素行为
}

\author{
古晓锋，刘贻灿 ${ }^{*}$, 邓亮鹏 \\ 中国科学院壳幔物质与环境重点实验室, 中国科学技术大学地球和空间科学学院, 合肥 230026 \\ *联系人, E-mail: liuyc@ustc.edu.cn \\ 2013-06-03 收稿, 2013-06-14 接受, 2013-07-30 网络版发表 \\ 国家重点基础研究发展计划(2009CB825002)和国家自然科学基金(41273036, 40973043)资助
}

\begin{abstract}
摘要 变质岩石学、同位素年代学和地球化学研究表明, 北大别罗田榴辉岩在俯冲和折返 过程中经历了超高压变质作用以及多阶段的高温变质过程, 并导致了一系列矿物以及元 素和同位素组成的变化. 从超高压榴辉岩相到高压麻粒岩相, 经历了多阶段 $>900^{\circ} \mathrm{C}$ 的近 等温减压变质过程. 通过锆石 U-Pb 定年及矿物包体和微量元素分析, 限定了超高压榴辉 岩相、高压榴辉岩相和麻粒岩相变质时代分别为 $226 \pm 2,214 \pm 2$ 和 $207 \pm 4 \mathrm{Ma}$, 并确定了两 期角闪岩相变质和燕山期热事件影响与部分熔融的时代. 根据元素和同位素地球化学研

究, 证明罗田榴辉岩是由新元古代镁铁质下地壳岩石在三叠纪发生超高压变质形成的, 其原岩是由幔源岩浆在新元古代侵位过程中不同程度地混染古老地壳物质形成的辉长岩 和少量玄武岩, 并且在超高压岩石折返过程中受到了部分熔融和流体活动的影响与改造, 造成了元素和同位素组成的不同变化. 在此基础之上, 获得了折返初期发生部分熔融的 同位素年代学和地球化学证据.
\end{abstract}

关键词

榴辉岩

镁铁质下地壳

超高压变质作用

多阶段高温变质过程 部分熔融
高压-超高压变质带中榴辉岩及相关岩石是大陆 俯冲、碰撞和折返过程的最重要见证者, 它们提供了 造山带形成和演化的重要证据和信息, 而超高压变 质岩的形成与折返机制则是变质岩石学和大陆动力 学研究方面的热点和前沿问题之一. 大别-苏鲁造山 带因出露规模巨大的含柯石英和金刚石超高压变质 带以及发育与大陆俯冲和折返过程有关的构造岩石 单位而闻名于世, 为研究大陆碰撞造山带的形成和 演化过程以及超高压岩石的形成与折返机制等提供 了重要的天然实验室. 大别山位于秦岭-大别-苏鲁造 山带的中部, 它是三叠纪华南板块向华北板块之下 俯冲形成的碰撞型造山带, 主要包括宿松变质带、南 大别低温榴辉岩带、中大别超高压变质带、北大别杂 岩带及北淮阳带等构造岩石单位 ${ }^{[13]}$. 其中, 南大别
低温榴辉岩带、中大别超高压变质带和北大别杂岩带 是 3 个含榴辉岩的岩石单位, 简称南大别、中大别和 北大别.

先前研究已证明, 北大别经历了三叠纪大陆深 俯冲和超高压变质作用以及多阶段变质演化 ${ }^{[3]}$, 但是 仍缺乏柯石英等超高压矿物学证据、限定其俯冲和折 返过程的确切时代、榴辉岩原岩性质和岩石成因的关 键证据以及其在折返过程中的元素和同位素行为探 讨. 为此, 我们对北大别罗田榴辉岩进行了系统的岩 石学、锆石 U-Pb 年代学、锆石矿物包体和微量元素 以及岩石地球化学和 Sr-Nd-Pb-Hf 同位素地球化学等 方面的综合研究, 确定了罗田榴辉岩俯冲和折返过 程的多阶段变质时代、查明了其原岩性质和岩石成因, 并探讨了其在折返期间的元素和同位素行为. 


\section{1 超高压变质作用和多阶段高温变质证据}

\section{1 柯石英和柯石英假象等超高压变质的矿物学 证据}

罗田榴辉岩遭受了强烈的退变质作用，表现出 多期减压变质结构而极少保留峰期变质矿物和早期
超高压变质证据 ${ }^{[3,4]}$. 大多数仅保留石榴子石和金红 石以及少量绿辉石包体，广泛发育因减压形成的、由 透辉石 + 紫苏辉石 + 斜长石等和角闪石 + 斜长石等组 成的两期后成合晶(图1(a))或针状矿物出溶体(图2(a)), 表明经历过麻粒岩相变质叠加和角闪岩相退变质作 用。石榴子石中发现有石英(图 1(b)) 和多晶石
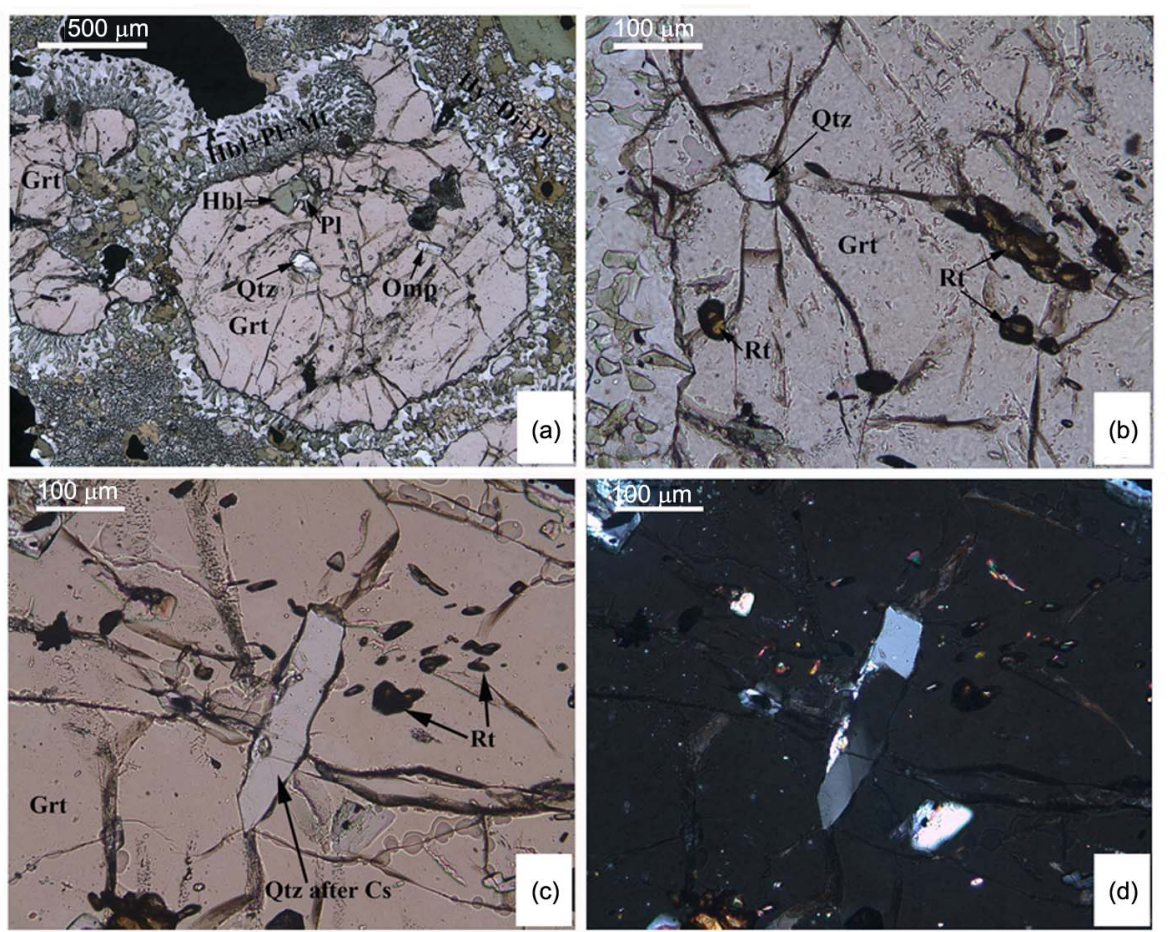

图 1 罗田榴辉岩显微照片

据文献[4]修改. (a) 石榴子石中绿辉石和石英包体以及麻粒岩相和角闪岩相退变质作用形成的两期后成合晶; (b) 石榴子石中石英和金红石包 体; (c)和(d) 石榴子石中多晶石英包体(柯石英假象). 矿物缩写: Grt, 石榴子石; Cpx, 单斜辉石; Rt, 金红石; Hy, 紫苏辉石; Qtz, 石英; Cs, 柯 石英; Omp, 绿辉石; $\mathrm{Hbl}$, 角闪石; $\mathrm{Pl}$, 斜长石; $\mathrm{Di}$, 透辉石; $\mathrm{Mt}$, 磁铁矿
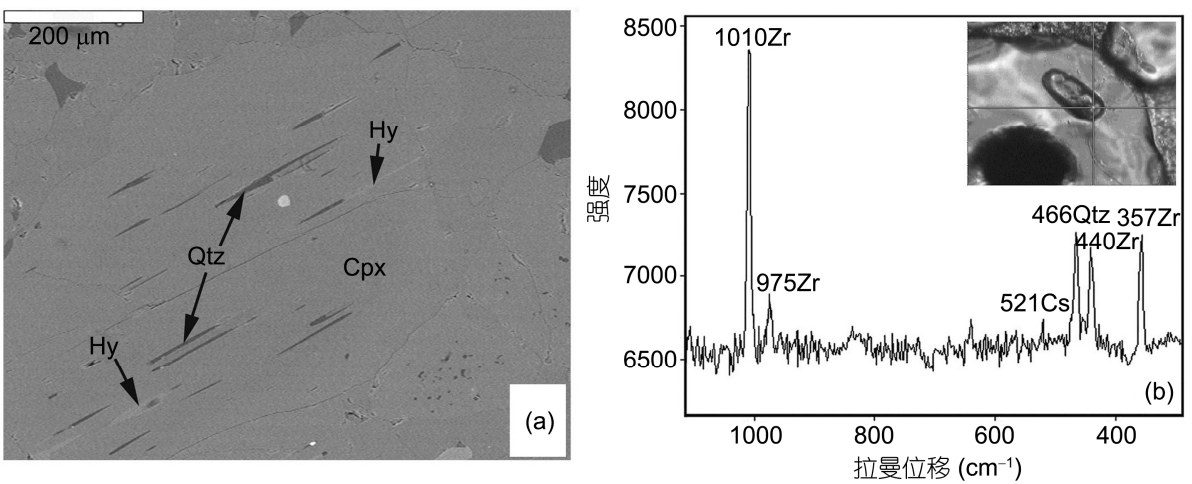

图 2 罗田榴辉岩显微照片和激光拉曼曲线

据文献[4]修改. (a) 单斜辉石中紫苏辉石和石英针状出溶体; (b) 三叠纪变质钻石中柯石英和石英包体的激光拉曼曲线. 矿物缩写: Cpx, 单斜 辉石; $\mathrm{Hy}$, 紫苏辉石; $\mathrm{Qtz}$, 石英; Cs, 柯石英; $\mathrm{Zr}$, 铅石 
英(图 1(c), (d))包体, 偶尔在锆石中发现柯石英残晶 (图 2(b)), 证明罗田榴辉岩经历了超高压变质作用. 此外, 单斜辉石中发育石英+斜长石 + 角闪石等针状 出溶体以及石榴子石中发育金红石 + 单斜辉石 + 角闪 石土磷灰石出溶体, 表明它们曾分别是超 $\mathrm{Si}$ 、富 $\mathrm{Na}$ 的绿辉石和石榴子石, 应形成于 $5 \sim 7 \mathrm{GPa}$ 的超高压条 件下 ${ }^{[4]}$. 结合北大别北部榴辉岩和片麻岩中金刚石的 发现 ${ }^{[5,6]}$, 证明北大别整体经历了超高压变质作用.

\section{2 多阶段高温变质证据}

鉴于北大别带经历了多阶段变质演化, 特别是 麻粒岩相和角闪岩相的变质叠加, 造成早期的变质 矿物或证据已完全或部分消失, 从而大大地影响了 变质条件的估算. 为此, 我们利用副矿物微量元素温 度计对罗田榴辉岩中金红石中 $\mathrm{Zr}$ 和锆石中 $\mathrm{Ti}$ 温度进 行了计算(图 3 和 4). 结果显示, 大多数变质锆石给 出了较低的温度 $650 \pm 50^{\circ} \mathrm{C}$, 只有少数最高温度数据 $>900^{\circ} \mathrm{C}$. 这些低的锆石 $\mathrm{Ti}$ 含量温度可能与锆石生长 介质中 $\mathrm{Ti}$ 的活度有关, 或者代表角闪岩相退变质过 程中锆石重结晶温度; 由于锆石中 $\mathrm{Ti}$ 具有高的封闭 温度, 因此高的 $\mathrm{Ti}$ 含量温度可能代表近于真实的变 质温度. 结合传统的石榴子石-绿辉石和单斜辉石-斜 方辉石矿物对 $\mathrm{Fe}-\mathrm{Mg}$ 配分地质温度计, 得到罗田榴 辉岩经历了从超高压榴辉岩相 $\rightarrow$ 石英榴辉岩相 $\rightarrow$ 麻 粒岩相等多阶段 $>900{ }^{\circ} \mathrm{C}$ 的高温变质过程 ${ }^{[4,7,8]}$. 其中, 超高压榴辉岩相变质温度为 $T=910 \sim 1050^{\circ} \mathrm{C}(P=4$

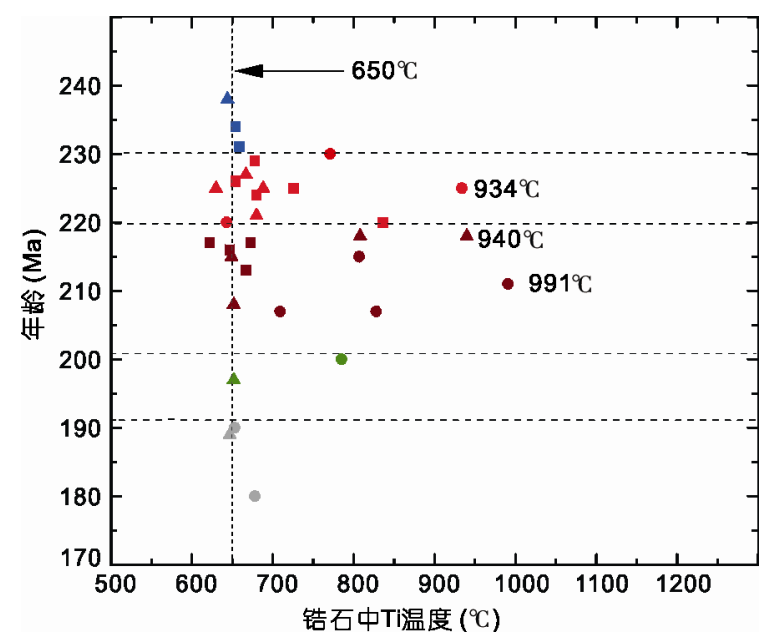

图 3 北大别罗田榴辉岩中变质锆石 U-Pb 年龄与 $\mathbf{T i}$ 含量温度 之间的关系 ${ }^{[8]}$

图中相同符号的数据点来自同一样品, 不同颜色代表不同变质阶段 年龄和温度

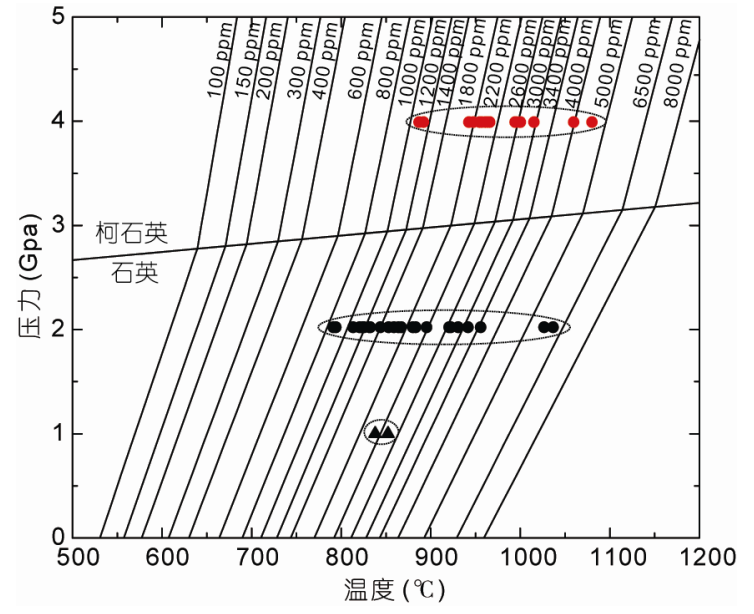

图 4 罗田榴辉岩的变质锆石中包体金红石 $\mathrm{Zr}$ 含量与温度压力之间的关系 ${ }^{[8]}$

红圆点、黑圆点和黑三角点分别表示年龄为 220 230, 210 220 和 200 210 Ma 变质锆石区域金红石包体数据. $1 \mathrm{ppm}=1 \mu \mathrm{g} \mathrm{g}^{-1}$

$\mathrm{GPa})$ 、高压榴辉岩相变质温度为 $T=940 \sim 1050^{\circ} \mathrm{C}(P=$ $2 \mathrm{GPa})$ 和麻粒岩相变质叠加的温度为 $T=905 \sim 917^{\circ} \mathrm{C}$ $(P=1.1 \sim 1.4 \mathrm{GPa})$. 麻粒岩相变质温度是根据单斜辉 石与其中紫苏辉石出溶体(图 2(a))计算的矿物对平衡 温度 ${ }^{[4]}$. 这与由麻粒岩相后成合晶中单斜辉石-斜方 辉石矿物对计算得出的变质温度结果 (最高达 $\left.909^{\circ} \mathrm{C}\right)^{[9]}$ 以及有关报道 ${ }^{[10]}$ 一致. 由此证明, 北大别榴 辉岩的高压麻粒岩相退变质温度应为 $910^{\circ} \mathrm{C}$ 左右, 属 于超高温变质作用.

根据上述结果, 可见罗田榴辉岩从超高压榴辉 岩相 $\rightarrow$ 高压榴辉岩相 $\rightarrow$ 麻粒岩相变质阶段, 处于高 温 $\left(>900^{\circ} \mathrm{C}\right)$ 条件下近等温减压过程. 对于这样长时间 的高温减压过程, 不仅有可能使超高压岩石部分或 全部转变为低压矿物组合, 造成北大别榴辉岩及相 关岩石中很难发现柯石英等超高压变质证据, 而且 还可能引起矿物同位素体系的再造, 以致难以精确 测定不同变质阶段的同位素年龄. 另一方面, 引起榴 辉岩及相关岩石发生部分熔融作用, 这与获得的元 素地球化学方面证据相吻合.

\section{2 俯冲和折返过程的同位素年代学制约}

针对北大别罗田榴辉岩经历了多期变质演化和 高温过程, 我们对罗田穹隆不同地点的榴辉岩进行 了锆石 U-Pb 定年以及矿物包体和微量元素研究. 结 果表明, 该区榴辉岩具有一致的多期 ${ }^{206} \mathrm{~Pb} /{ }^{238} \mathrm{U}$ 谐和 年龄记录(图 5), 包括原岩年龄为 780 800 $\mathrm{Ma}$, 以及 


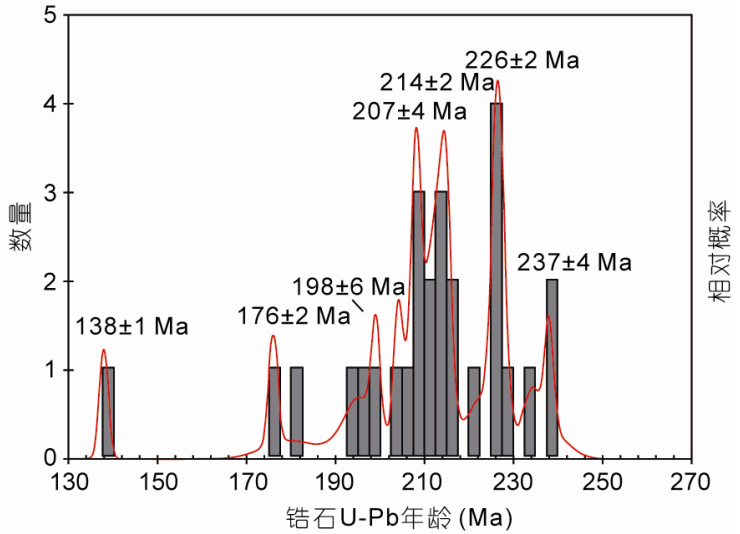

图 5 北大别罗田榴辉岩的多期变质锆石 U-Pb 年龄统计曲线

$237 \pm 4,226 \pm 2,214 \pm 2,207 \pm 4,198 \pm 6,176 \pm 2$ 和 $138 \pm 1$ $\mathrm{Ma}$ 等多期变质年龄, 此外还有 $1609 \pm 6 \mathrm{Ma}$ 古老继承 锆石的表面年龄. 其中年龄为 $226 \pm 2$ 和 $214 \pm 2 \mathrm{Ma}$ 的 锆石区域都表现为扁平的 HREE 配分模式并且没有 $\mathrm{Eu}$ 异常, 具有典型的榴辉岩相变质锆石特点. $226 \pm 2$ $\mathrm{Ma}$ 锆石区域主要包含高 $\mathrm{Ca}$ 石榴子石+高 $\mathrm{Na}$ 绿辉石 $(\mathrm{Jd}=40 \sim 50)+$ 金红石 + 文石 + 柯石英等超高压矿物组 合包裹体, $214 \pm 2 \mathrm{Ma}$ 锆石区域则含有低 $\mathrm{Ca}$ 石榴子石 + 低 $\mathrm{Na}$ 绿辉石 $(\mathrm{Jd}=20 \sim 30)+$ 金红石+石英等矿物包裹 体, 表明它们分别形成于超高压和高压榴辉岩相 ${ }^{[7]}$. 因此, $226 \pm 2$ 和 $214 \pm 2 \mathrm{Ma}$ 分别代表了超高压和高压榴 辉岩相变质时代. 年龄为 $207 \pm 4 \mathrm{Ma}$ 的变质锆石域则 具有平坦的 HREE 配分模式以及无到负的 $\mathrm{Eu}$ 异常, 通常没有矿物包裹体, 可能代表了麻粒岩相变质时 代. 另外，一颗年龄为 $206 \pm 5 \mathrm{Ma}$ 的锆石域具有弱的 岩浆结晶环带、陡峭的 HREE 配分模式和很高的 LREE 含量, 可能是从部分熔融产生的熔体中结晶形 成的，指示在折返初期发生过减压熔融作用. $237 \pm 4$ $\mathrm{Ma}$ 的锆石域具有低的 $\mathrm{Th} / \mathrm{U}$ 比值 $(<0.1)$ 和平坦的 HREE 配分模式并显示 Eu 负异常, 代表了超高压榴 辉岩相之前的前进变质时代, 而 $138 \pm 1 \mathrm{Ma}$ 则证明罗 田榴辉岩受到了早白严纪构造热事件的影响. 但是, $198 \pm 6$ 和 $176 \pm 2 \mathrm{Ma}$ 的锆石 $\mathrm{U}-\mathrm{Pb}$ 年龄意义因为缺乏变 质矿物包体制约, 是否代表两期角闪岩相退变质时 代尚需要更多的同位素年代学、矿物包体和微量元素 等数据给予限定.

对 3 个榴辉岩样品进行了石榴子石 + 单斜辉石 + 全岩 $\mathrm{Sm}-\mathrm{Nd}$ 等时线定年, 分别给出了 $199 \pm 2,174 \pm 1$ 和 $173 \pm 7 \mathrm{Ma}$ 的年龄，与锆石年龄 $198 \pm 6$ 和 $176 \pm 2 \mathrm{Ma}$ 分别在误差范围内一致. 石榴子石中 $\mathrm{Sm}-\mathrm{Nd}$ 等时线
封闭温度一般约 700 800 ${ }^{\circ} \mathrm{C}$ (详见文献[11]), 远低于 罗田榴辉岩的榴辉岩相和高压麻粒岩相变质温度 $\left(>900{ }^{\circ} \mathrm{C}\right)$, 但是类似于角闪岩相阶段变质温度 $\left(706 \sim 777^{\circ} \mathrm{C}\right)^{[3,4]}$. 此外, $198 \pm 6 \mathrm{Ma}$ 与 Wang 等人 ${ }^{[12]}$ 确 定的北大别角闪岩相退变质时代(199.9 $\pm 3 \mathrm{Ma})$ 一致, 可能代表了早期角闪岩相退变质时代. 而 $174 \pm 1 \mathrm{Ma}$ 则可能是晚期角闪岩相退变质时代. 因此, 北大别可 能存在两期角闪岩相退变质作用, 这与前人的岩石 学研究结果 ${ }^{[13,14]}$ 一致.

角闪石 $\mathrm{Ar}-\mathrm{Ar}$ 和金红石 $\mathrm{U}-\mathrm{Pb}$ 定年给出了一致的 年龄记录, 分别为 $122 \pm 1 \sim 128 \pm 3 \mathrm{Ma}$ 和 $128 \pm 11 \sim$ $135 \pm 12 \mathrm{Ma}$ ，提供了罗田榴辉岩受早白严世热事件影 响的同位素年代学证据. 由于角闪石形成于角闪岩 相退变质阶段，而金红石则形成于榴辉岩相变质条 件下，但是角闪石 $\mathrm{Ar}-\mathrm{Ar}$ 和金红石 U-Pb 体系的封闭 温度都比较低 $\left(\sim 500{ }^{\circ} \mathrm{C}\right)$, 因此这两种方法得到的 $\sim 130 \mathrm{Ma}$ 年龄, 代表了受到加热之后的冷却年龄和部 分熔融的时代; 而 $138 \pm 1 \mathrm{Ma}$ 的锆石 U-Pb 年龄, 则可 能代表了罗田榴辉岩受到改造的真正时代, 与侯振 辉等人 ${ }^{[15]}$ 对惠兰山麻粒岩的研究结果一致, 限定了 大别造山带的去山根起始时间.

\section{3 原岩性质和岩石成因}

罗田榴辉岩在稀土元素球粒陨石标准化图解上 表现出微弱负的到正的 $\mathrm{Eu}$ 异常, 结合 $\mathrm{SiO}_{2}-\mathrm{Zr} / \mathrm{TiO}_{2}$ 和 $\mathrm{Zr} / \mathrm{TiO}_{2}-\mathrm{Nb} / \mathrm{Y}$ 图解, 表明它们的原岩主要是辉长 岩, 以及少量玄武岩. 根据稀土元素和微量元素的差 异，这些榴辉岩可以分成两类. 第一类具有富集 LREE 和 LILE 的特征, 类似于下地壳的平均组成 ${ }^{[16]}$, 另一类则具有亏损 LREE 和 LILE 的特征，但是它们 的 HFSE 和 HREE 等不活动元素也与下地壳平均值 ${ }^{[16]}$ 一致. 此外, 罗田榴辉岩具有类似于下地壳岩石的低 放射性成因 $\mathrm{Pb}$ 同位素组成，明显不同于中大别超高 压岩石所具有的高放射性成因 $\mathrm{Pb}$ 同位素特征 ${ }^{[17,18]}$. 因此, 提供了罗田榴辉岩的原岩为镁铁质下地壳岩 石的地球化学证据.

这些榴辉岩样品的全岩初始 $\mathrm{Sr}-\mathrm{Nd}$ 同位素组成 (取 $t=220 \mathrm{Ma}$ ) 分别为 ${ }^{87} \mathrm{Sr} /{ }^{86} \mathrm{Sr}=0.704422 \sim 0.706927$ 和 $\varepsilon_{\mathrm{Nd}}(t)=-12.4 \sim-1.4$, 并可以根据 $\varepsilon_{\mathrm{Nd}}(t)$ 值进一步被分为 (-12.4 -7.3)和 $(-6.0 \sim-1.4)$ 两类. 明显地, 第一类榴 辉岩比第二类含有更多的古老地壳组分. 但是当回 算到原岩形成时代 $790 \mathrm{Ma}$ 时, 大多数样品的全岩 
$\varepsilon_{\mathrm{Nd}}(t)$ 值都表现出离散的趋势, 表明它们可能受到后 期变质改造的影响, 然而第二类榴辉岩中有一个样 品表现出具有正的 $\varepsilon_{\mathrm{Nd}}(t)$ 值 $(+1.7)$, 证明这些榴辉岩的 原岩起源于新元古代的幔源岩浆作用. 它们的新元 古代岩浆锆石 $\mathrm{Hf}$ 同位素组成(图 6)也表现出与全岩 $\mathrm{Nd}$ 同位素特征一致的结果,一类显示出较低的 $\varepsilon_{\mathrm{Hf}}(790 \mathrm{Ma})$ 值(-9.5 +0.6), 表明它们的原岩中古老地 壳的 Hf 同位素组成占主导地位, 另一类则具有较高 的 $\varepsilon_{\mathrm{Hf}}(790 \mathrm{Ma})$ 值 $(+2.6 \sim+7.9)$, 其中含有更多的新生地 壳组分. 此外, 在第一类榴辉岩中有表面年龄为 $1609 \pm 6 \mathrm{Ma}$ 的古老继承锆石, 其单阶段和两阶段 $\mathrm{Hf}$ 模式年龄均为 $2.15 \mathrm{Ga}$ 以及对应的正 $\varepsilon_{\mathrm{Hf}}(t)$ 值 $(+9.6)$, 表明古元古代有一期新生地壳增生事件, 并形成该 区新元古代时古老地壳的一部分. 因此, 罗田榴辉岩 的原岩是在新元古代幔源岩浆底侵过程中, 不同程 度地混染了古老下地壳物质而形成的辉长岩和少量 玄武岩.

\section{4 折返期间元素和同位素行为}

罗田榴辉岩在俯冲和折返过程中经历了多阶段

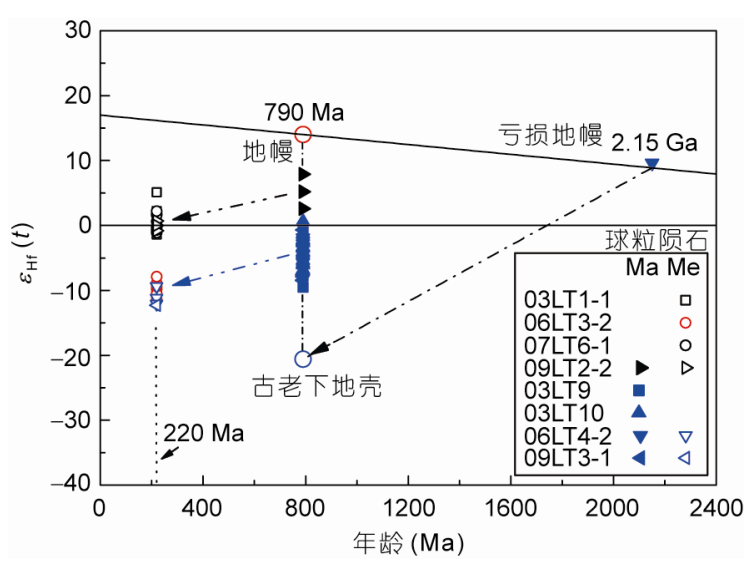

图 6 罗田榴辉岩的锆石 Hf 同位素演化模式 $\mathrm{Ma}$, 岩浆锆石; $\mathrm{Me}$, 变质锆石
变质演化, 表现出明显的从富集到强烈亏损的元素 变化. 全岩 $\mathrm{Sr}-\mathrm{Nd}$ 同位素研究表明, 这些元素组成的 变化是三叠纪变质改造的结果. 在 $\mathrm{Rb} / \mathrm{Yb}-\mathrm{Nb} / \mathrm{La}$ 图解 上, 一些样品显示出 LILE 相对于 LREE 富集的特征, 还有一些样品则表现为 LILE 和 LREE 都强烈亏损. 这表明榴辉岩中元素的活动性不仅受到了流体活动 的影响, 而且还受到了部分熔融作用的改造.

正如前文所述, 本文研究的榴辉岩是由镁铁质 下地壳岩石俯冲变质成因, 通常缺水 ${ }^{[3,4]}$. 但是折返 期间，名义上无水矿物中的结构水和分子水因为减 压释放形成的流体活动 ${ }^{[19]}$, 明显地改变了部分罗田 榴辉岩的 LILE 和 Rb-Sr 同位素特征. 一些样品表现 出明显的 Rb, Ba, K 等元素相对于 LREE 富集的特征, 还有一些则显示强烈亏损水溶性元素、而 $T h, U$ 和 LREE 元素却相对富集的特点, 表明角闪岩相退变质 阶段的流体有不同的来源. 来自围岩片麻岩的富含 水溶性元素的外部流体造成与片麻岩接触的榴辉岩 中 LILE 含量的显著增加, 而部分榴辉岩则因为流体 释放损失了大量的水溶性元素.

此外, 一些榴辉岩样品强烈亏损 LREE 和 LILE, 并且它们的 $\mathrm{Sr}-\mathrm{Nd}$ 同位素成分也发生了显著的变化. 这可能是因为部分熔融作用产生的富集 LREE 和 LILE 元素的熔体萃取的结果 ${ }^{[20,21]}$. Zhao 等人 ${ }^{[22]}$ 在研 究苏鲁造山带大陆深钻榴辉岩时, 也发现部分样品 亏损 LREE 和 LILE, 并将其解释为岩石受到部分熔 融发生熔体萃取的结果. 罗田榴辉岩从超高压榴辉 岩相到高压麻粒岩相的 $>900{ }^{\circ} \mathrm{C}$ 的高温条件下的折返 过程 ${ }^{[4,7,8]}$ 为部分熔融的发生提供了重要条件. 同时, 板船山的 6 个榴辉岩全岩给出了一个 $206 \pm 9$ Ma 的 Sm-Nd 同位素等时线年龄. 这个年龄与麻粒岩相变 质锆石的 $\mathrm{U}-\mathrm{Pb}$ 年龄 $(207 \pm 4 \mathrm{Ma})$ 在误差范围内一致, 也与从部分熔融产生的熔体中结晶的锆石年龄 $206 \pm 4 \mathrm{Ma}$ 一致, 表明榴辉岩中 LREE 和 LILE 等元素 的强烈亏损发生在折返初期的麻粒岩相变质阶段.

\section{参考文献}

1 徐树桐, 刘贻灿, 江来利, 等. 大别山造山带的构造几何学和运动学. 合肥：中国科学技术大学出版社, 2002. 1-133

2 Zheng Y F, Zhou J B, Wu Y, et al. Low-grade metamorphic rocks in the Dabie-Sulu orogenic belt: A passive-margin accretionary wedge deformed during continent subduction. Int Geol Rev, 2005, 47: 851-871

3 Liu Y C, Li S, Gu X, et al. Ultrhigh-pressure eclogite transformed from mafic granulite in the Dabie orogen. J Metamorph Geol, 2007, 25: 975-989 
4 Liu Y C, Gu X F, Rolfo F, et al. Ultrahigh-pressure metamorphism and multistage exhumation of eclogite of the Luotian dome, North Dabie Complex Zone (central China): Evidence from mineral inclusions and decompression textures. J Asian Earth Sci, 2011, 42: $607-617$

5 Xu S T, Liu Y C, Chen G B, et al. Microdiamonds, their classification and tectonic implications for the host eclogites from the Dabie and $\mathrm{Su}-\mathrm{Lu}$ regions in central eastern China. Mineral Mag, 2005, 69: 509-520

6 Liu Y C, Li S, Xu S. Zircon SHRIMP U-Pb dating for gneiss in northern Dabie high T/P metamorphic zone, central China: Implication for decoupling within subducted continental crust. Lithos, 2007, 96: 170-185

7 Liu Y C, Gu X F, Li S G, et al. Multistage metamorphic events in granulitized eclogites from the North Dabie complex zone, central China: Evidence from zircon U-Pb age, trace element and mineral inclusion. Lithos, 2011, 122: 107-121

8 Liu Y C, Deng L P, Gu X F, et al. Application of Ti-in-zircon and Zr-in-rutile thermometers to constrain long-lived high-temperature metamorphism in granulitized eclogites from the Dabie orogen, central China. Gondwana Res, 2013, 24

9 刘贻灿, 徐树桐, 李曙光, 等. 大别山北部镁铁-超镁铁质岩带中榴辉岩的分布与变质温压条件. 地质学报, 2001, 75: 385-395

10 Tong L, Jahn B M, Zheng Y F. Diverse $P-T$ paths of the northern Dabie complex in central China and its reworking in the early Cretaceous. J Asian Earth Sci, 2011, 42: 633-640

11 Jung S, Mezger K. Geochronology in migmatites-A Sm-Nd, U-Pb and Rb-Sr study from the Proterozoic Damara belt (Namibia): implications for polyphase development of migmatites in high-grade terranes. J Metamorph Geol, 2001, 19: 77-97

12 Wang S J, Li S G, An S C, et al. A granulite record of multistage metamorphism and REE behavior in the Dabie orogen: Constrains from zircon and rock-forming minerals. Lithos, 2012, 136-139: 109-125

13 Zhang R Y, Liou J G, Tsai C H. Petrogenesis of a high-temperature metamorphic Terrain: A new tetonic interpretation for the north Dabie Shan, central China. J Metamorph Geol, 1996,14: 319-333

14 Malaspina N, Hermann J, Scambelluri M, et al. Multistage metasomatism in ultrahigh-pressure mafic rocks from the North Dabie Complex (China). Lithos, 2006, 90: 19-42

15 侯振辉, 李曙光, 陈能松, 等. 大别造山带惠兰山镁铁质麻粒岩 Sm-Nd 和锆石 SHRIMP U-Pb 年代学及锆石微量元素地球化学. 中 国科学 D 辑: 地球科学, 2005, 35: 1103-1111

16 Rudnick R L, Gao S. Composition of the continental crust. In: Holland H D, Turekian K K, eds. Treatise on Geochemistry. Oxford: Elsevier, 2003. 1-64

17 Zhang H F, Gao S, Zhong Z Q, et al. Geochemical and Sr-Nd-Pb isotopic compositions of Cretaceous granitoids: Constraints on tectonic framework and crustal structure of the Dabieshan ultrahigh-pressure metamorphic belt, China. Chem Geol, 2002, 186: 281-299

18 李曙光，黄方，周红英，等. 大别山双河超高压变质岩及北部片麻岩的 U-Pb 同位素组成一一对超高压岩石折返机制的制约. 中国 科学 D 辑: 地球科学, 2001, 31: 977-984

19 Zheng Y F. Fluid regime in continental subduction zones: Petrological insights from ultrahigh-pressure metamorphic rocks. J Geol Soc London, 2009, 166: 763-782

20 Shatsky V S, Jagoutz E, Sobolev N V, et al. Geochemistry and age of ultrahigh pressure metamorphic rocks from the Kokchetav massif (Northern Kazakhstan). Contrib Mineral Petrol, 1999, 137: 185-205

21 Hermann J, Rubatto D, Korsakov A. Multiple zircon growth during fast exhumation of diamondiferous, deeply subducted continental crust (Kokchetav Massif, Kazakhstan). Contrib Mineral Petrol, 2001, 141: 66-82

22 Zhao Z F, Zheng Y F, Chen R X, et al. Element mobility in mafic and felsic ultrahigh-pressure metamorphic rocks during continental collision. Geochim Cosmochim Acta, 2007, 71: 5244-5266 